\title{
Identification and Molecular Mapping of a Gummy Stem Blight Resistance Gene in Wild Watermelon (Citrullus amarus) Germplasm PI 189225
}

\author{
Runsheng Ren, ${ }^{\dagger}$ Jinhua Xu, Man Zhang, Guang Liu, Xiefeng Yao, Lingli Zhu, and Qian Hou \\ Jiangsu Key Laboratory for Horticultural Crop Genetic, Improvement/Institute of Vegetable, Jiangsu, Academy of Agricultural \\ Sciences, Nanjing, Jiangsu, China
}

\begin{abstract}
Gummy stem blight (GSB), caused by Stagonosporopsis cucurbitacearum (syn. Didymella bryoniae), is a destructive foliar disease of watermelon in areas with hot and humid climates. The wild watermelon germplasm PI 189225 is a known source of resistance to GSB. The identification and use of molecular markers linked to resistance genes in the wild-type germplasm will speed up the introgression of GSB resistance into new watermelon varieties. An $F_{2}$ segregating population was obtained from a cross between the resistant wild watermelon genotype PI 189225 and the susceptible genotype K3. The $\mathrm{F}_{2}$-derived $\mathrm{F}_{3}$ families were inoculated with a single isolate of $S$. cucurbitacearum (JS002) from Jiangsu Academy of Agricultural Sciences. The results of the genetic analysis demonstrated that GSB resistance in PI 189225 was controlled by a major quantitative trait locus (QTL), temporarily designated Qgsb8.1. Based on the results of bulk sergeant analysis and sequencing,

result of a QTL linkage analysis with Kompetitive allele-specific PCR (KASP) SNP markers further mapped the GSB resistance locus between the SNP markers KASP_JS9383 and KASP_JS9168 in a region of $571.27 \mathrm{~kb}$ on chromosome 8 . According to the watermelon gene annotation database, the region contains approximately 19 annotated genes and, of these 19 genes, 2 are disease resistance gene analogs: Cla001017 (coiled-coil nucleotide-binding site leucine-rich repeat resistance protein) and Cla001019 (pathogenesis related). Reverse-transcription quantitative PCR demonstrated that the expression of the two genes changed following $S$. cucurbitacearum infection, suggesting that they play important roles in GSB resistance in watermelon. This result will facilitate fine mapping and cloning of the $Q g s b 8.1$ locus, and the linked markers will further provide a useful tool for marker-assisted selection of this locus in watermelon breeding programs.
\end{abstract} one associated region spanning $5.7 \mathrm{Mb}(10,358,659$ to $16,101,517)$ on chromosome 8 was identified as responsible for the resistance to GSB using the $\Delta$ (single-nucleotide polymorphism [SNP]-index) method. The
Keywords: gummy stem blight, molecular marker, resistance gene, wild watermelon germplasm
Watermelon (Citrullus lanatus (Thunb.) Matsum. \& Nakai) is a globally important vegetable fruit crop. The total yield in 2017 was over 100 million tons, accounting for $10.8 \%$ of total vegetable production (FAO Statistics 2017; http://www.fao.org/faostat/zh/\#data/QC).

Gummy stem blight (GSB), caused by Stagonosporopsis cucurbitacearum (Fr.) Aveskamp, Gruyter \& Verkley (syn. Didymella bryoniae), is a major fungal disease of watermelon and other cucurbits in areas with hot and humid climates (Keinath et al. 1995; Stewart et al. 2015; van Steekelenburg 1981, 1983, 1984, 1985a,b). The disease can cause crown blight, extensive defoliation, fruit rot, and loss of fruit during storage and transportation (Norton 1979; Sowell and Pointer 1962). Yield losses attributed to GSB in watermelon production can reach as high as $100 \%$ in watermelon-growing regions with high disease pressure (St. Amand and Wehner 1995a; Power et al. 1992; Sitterly and Keinath 1996). In recent years, many types of fungicides have been applied to control GSB disease; however, only partial control of the disease can be achieved with fungicides. The use of fungicides also causes serious environmental problems and may

${ }^{\dagger}$ Corresponding author: R. Ren; runshengren@163.com

Funding: This work was supported by grants from the National Natural Science Foundation of China (number 31601777) and the Jiangsu Provincial Support Program for Breeding New Varieties (PZCZ201716).

*The $\boldsymbol{e}$-Xtra logo stands for "electronic extra" and indicates that one supplementary table is published online.

The author(s) declare no conflict of interest.

Accepted for publication 18 August 2019.

(C) 2020 The American Phytopathological Society induce fungicide resistance. Utilization of host resistance is considered to be the most important and preferred method to control the disease.

Owing to the narrow genetic diversity in cultivated watermelon (Levi et al. 2001a,b; Yang et al. 2016), wild watermelon germplasms with high levels of resistance to diseases and other stresses provide important sources for watermelon improvement. The wild watermelon germplasm PI 189225 has been reported to be resistant to GSB (Gusmini et al. 2005, 2017), powdery mildew (Tetteh et al. 2010, 2013), and anthracnose (Boyhan et al. 1994b). To effectively utilize the comparably high level of resistance against GSB in PI 189225 , it is necessary to determine the mode of inheritance and identify the molecular markers linked to GSB resistance.

With the development of next-generation sequencing (NGS) technologies and the availability of reference genome sequences of watermelon, bulked segregant analysis (BSA) in combination with whole-genome resequencing is regarded as an efficient and costeffective approach to rapidly locate genomic regions containing genes or quantitative trait loci (QTL) affecting traits of interest (Liu et al. 2012; Mokry et al. 2011; Takagi et al. 2013). This approach have been successfully applied in several plant species, including Oryza sativa (Abe et al. 2012; Takagi et al. 2013), Zea mays (Haase et al. 2015; Liu et al. 2012; Silva et al. 2012; Xu et al. 2014), Hordeum vulgare (Mascher et al. 2014), Cucumis sativus (Lu et al. 2014), Brassica rapa (Wang et al. 2016), B. juncea (Zhao et al. 2017), B. napus (Yao et al. 2017), Allium cepa (Kim et al. 2015), and C. melo (Zhang et al. 2016).

In the present study, we employed BSA in combination with NGS (BSA-seq) and the Kompetitive allele-specific PCR (KASP) singlenucleotide polymorphism (SNP) genotyping method for identification and mapping of the GSB resistance loci in the wild watermelon germplasm PI 189225.

\section{Materials and Methods}

Plant materials and DNA extraction. The plant population consisted of $264 \mathrm{~F}_{2}$ individuals and $211 \mathrm{~F}_{2: 3}$ families derived from a 
cross with the cultivated watermelon breeding line K3 (Citrullus lanatus) as the female parent and the wild watermelon accession PI 189225 (C. amarus) as the male parent. The $\mathrm{F}_{2}$ population was first seeded in trays with 50 compartments $(5.0 \mathrm{~cm}$ in length by $5.0 \mathrm{~cm}$ in width by $4.5 \mathrm{~cm}$ in depth) filled with a standard potting medium (Pindstrup peat substrate; Pindstrup Horticulture Ltd., Ryomgård, Denmark) and grown in a growth room at optimal growth temperatures of 25 to $30^{\circ} \mathrm{C}$ for watermelon. Seedlings at the two-leaf stage were then transplanted to plastic greenhouse at the Luhe experimental base of the Jiangsu Academy of Agricultural Sciences (JAAS) $\left(118^{\circ} 621^{\prime} \mathrm{N}, 32^{\circ} 488^{\prime} \mathrm{E}\right)$, Nanjing, China, and compost fertilizer (consisting of $17 \% \mathrm{~N}, 17 \% \mathrm{P}_{2} \mathrm{O}_{5}$, and $17 \% \mathrm{~K}_{2} \mathrm{O}$; Jiangsu Xintiandi Amino Acid Fertilizers Ltd., Jiangsu, China) and organic fertilizer (consisting of poultry manure; Jiangsu Xintiandi Amino Acid Fertilizers Ltd.) were applied as base fertilizers before transplanting. The application rates were 50 and $1500 \mathrm{~kg} \mathrm{ha}^{-1}$ for compost fertilizer and organic fertilizer, respectively. The plants were grown in tworow plots of $50 \mathrm{~m}$, with $0.5 \mathrm{~m}$ between adjacent rows. The distances between plots and adjacent plants were 0.5 and $0.6 \mathrm{~m}$, respectively.

The $\mathrm{F}_{2}$ plants were self-pollinated to produce the $\mathrm{F}_{2: 3}$ generation. Each plant was tagged individually, and the plant identification was used in the plastic greenhouse to associate the $\mathrm{F}_{2}$ genotype with the corresponding phenotypes of the derived $\mathrm{F}_{2: 3}$ families. At 65 days after transplanting, flowers were checked frequently in the afternoon to determine the status of the flowers and both the female and the male flower buds were tagged, showing the date at the latest 1 day before anthesis, and also bagged by paper caps to prevent contamination. Self-pollination was carried out by hand between 9 and 11 A.M. of the next day using fresh pollen after the flowers opened. After pollination, paper caps were not removed until the fruit setting was observed. Standard cultivation management was followed throughout the growing season. At 40 days after pollination, watermelon seed were manually harvested.

Fungal isolate and conidial production. One virulent monoconidial isolate of $S$. cucurbitacearum (isolate JS002; JAAS), collected from Ningbo (eastern China), was used as the pathogen material; this isolate was identified and chosen based on its capacity for abundant sporulation and its aggressiveness ( $\mathrm{Li}$ et al. 2015). The conidial production was conducted following the procedure of $\mathrm{Li}$ et al. (2015). Briefly, small (5 $\mathrm{mm}$ in diameter) surface peels of cucumber fruit were first cut off with an approximate thickness of $1.5 \mathrm{~mm}$. Agar discs ( $5 \mathrm{~mm}$ in diameter) cut from the margins of actively growing S. cucurbitacearum colonies on potato dextrose agar were then subcultured on the cucumber fruit and incubated at $25^{\circ} \mathrm{C}$ with a $12-\mathrm{h}$ photoperiod and $90 \%$ relative humidity $(\mathrm{RH})$ for approximately 6 days. Cucumber tissues with black fruiting bodies were macerated, and the suspension was filtered through two layers of sterile cheesecloth and diluted in distilled water. The spore concentration was determined by counting in a hemocytometer under an Olympus BX41 microscope (Olympus, Tokyo, Japan) and adjusted to $1 \times 10^{6}$ conidia/ml for inoculation of plants.

GSB testing and statistical analysis. GSB testing was conducted in a greenhouse at JAAS during the spring and autumn seasons in 2016. Twenty-four plants from each of the parents, the $F_{1}$ generation, and the $\mathrm{F}_{2: 3}$ families were tested in the greenhouse. When the seedlings had grown to the four-leaf stage, they were inoculated by spraying a suspension of $S$. cucurbitacearum spores $\left(1 \times 10^{6}\right.$ conidia $\left./ \mathrm{ml}\right)$, to which $0.05 \%$ (vol/vol) Tween-20 had been added. This was followed by incubation at $25^{\circ} \mathrm{C}$ in a plastic mist tunnel at 90 to $100 \%$ $\mathrm{RH}$ for $24 \mathrm{~h}$ in the dark to promote spore germination and infection, and the plants were then kept in a greenhouse under natural light. For each $\mathrm{F}_{2: 3}$ family, each individual seedling was scored 10 days after inoculation based on a disease rating scale ranging from 0 to 9 , where $0=$ absence of GSB spots, $1=\leq 5 \%$ GSB spots, $3=>5 \%$ but $\leq 25 \%$ GSB spots, $5=>25 \%$ but $\leq 50$ GSB spots, $7=>50 \%$ but $\leq 75 \%$ GSB spots, and $9=>75 \%$ GSB spots or whole-leaf death. The disease index (DI) was calculated from the disease rating scale using the following formula: $\mathrm{DI}=100 \times \sum[$ (number of plants with disease rating $\times$ disease rating $) /($ total number of plants $\times$ highest disease rating possible)]. The disease rating scale was estimated by the percentage of symptomatic disease spot over the true leaves of each plant. Each of the two experiments was arranged in a completely randomized design with two replications, each consisting of $211 \mathrm{~F}_{2: 3}$ families.

Analysis of variance (ANOVA) was performed for DI to determine whether there were statistical differences among the $\mathrm{F}_{2: 3}$ families using the AOV function in QTL IciMapping (version 4.1) software with the default parameters. The data were also presented with means, ranges, and least significant difference. A Spearman correlation analyses was carried out between the DI from the two seasons using the statistical package of SPSS 19.0 (SPSS Inc., Chicago, IL, U.S.A.).

BSA and DNA extraction. Based on the GSB reactions of the $F_{2: 3}$ families, the corresponding $F_{2}$ individual plants were classified into three categories according to the DI: resistant (all plants resistant), intermediate (most plants susceptible and some resistant), and susceptible (all plants susceptible). The resistant and susceptible bulks were constructed by combining equal amounts of DNA from 12 homozygous resistant $F_{2}$ plants and 12 homozygous susceptible $F_{2}$ plants, respectively. Genomic DNA was extracted from freeze-dried leaf tissue collected from $\mathrm{F}_{2}$ seedlings using a cetyltrimethylammonium bromide method, as modified by Ren et al. (2015). DNA quality and concentration were determined by agarose gel analysis and spectrophotometry (NanoDrop ND-1000; Thermo Scientific, Wilmington, DE, U.S.A.), and the concentration was adjusted to be in the range of 50 to $100 \mathrm{ng} \mathrm{Hl}^{-1}$.

Construction of sequencing libraries and Illumina sequencing. Approximately $2 \mu \mathrm{g}$ of DNA from the two bulks and the two parental lines was used to construct paired-end sequencing libraries according to the manufacturer's instructions (Illumina TruSeq library construction). The constructed libraries were subjected to whole-genome resequencing with Illumina HiSeq 2500. Raw sequencing reads from the Illumina HiSeq 2500 system (Illumina) were subjected to quality control using FASTQC (Brown et al. 2017). Low-quality paired-end reads $(\mathrm{Q} \leq 5)$ with more than $50 \%$ bases in any single-end reads or the reads containing adapter (reads containing more than five adapterpolluted bases) or poly- $\mathrm{N}$ sequences (the number of $\mathrm{N}$ bases accounting for $>5 \%$ of total bases) were filtered. After removing adapters and lowquality reads, the clean reads were aligned against the reference genome of watermelon (97103 v1) by using Burrows-Wheeler Aligner software (Li and Durbin 2009). The Genome Analysis Toolkit was used to call SNPs and small indels across the parental lines and bulks with the standard filter method (McKenna et al. 2010).

SNP-index association analysis. SNP-index association analysis was used to determine genotype frequency differences between the two bulks (Abe et al. 2012) by calculating the $\Delta$ (SNP-index). In this study, M stands for the female parent (susceptible, K3), P stands for the male parent (resistant, PI 189225), aa denotes the genotype from the $\mathrm{R}$ pool, and ab denotes the $\mathrm{S}$ pool. $\Delta$ (SNP-index) values were calculated as follows: SNP-index $(\mathrm{ab})=\mathrm{Mab} /(\mathrm{Pab}+\mathrm{Mab})$, SNPindex $(\mathrm{aa})=\mathrm{Maa} /(\mathrm{Paa}+\mathrm{Maa})$, and $\Delta(\mathrm{SNP}-$-index $)=$ SNP-index $(\mathrm{aa})-$ SNP-index $(\mathrm{ab})$, where Mab indicates the depth of the ab population derived from $\mathrm{M}$ and $\mathrm{Pab}$ indicates the depth of the ab population derived from $\mathrm{P}$. Maa indicates the depth of the aa population derived from $\mathrm{M}$, and Paa indicates the depth of the aa population derived from P. A sliding window analysis was applied, averaging the $\Delta$ SNP-index values within a $1-\mathrm{Mb}$-sized window and $10-\mathrm{kb}$ step increment using an in-house-developed Python script (available on request) based on the program developed by Takagi et al. (2013). The average was plotted for all chromosomes and regions in which the average $\Delta$ (SNP-index) of a locus was more close to the target characteristic than that of surrounding regions, and windows that showed an average $P$ value $<0.01$ were considered candidate genomic regions harboring a locus associated with resistance to GSB.

Development and analysis of KASP markers. To develop markers, biallelic SNPs were randomly selected in the mapped regions according to a high-resolution genetic map constructed previously (Ren et al. 2015) and the watermelon reference genome sequence (Guo et al. 2013). The selected SNPs were first tested for their ability to differentiate the polymorphism by genotyping the two parents and a few $\mathrm{F}_{2}$ individuals with KASP genotyping assays at China Golden Marker Biotech Company (Beijing, China), and the primers that detected clear polymorphism were utilized to genotype the entire mapping population. 
One common reverse primer and two allele-specific forward primers based on the flanking sequences around the variant position (SNP) were designed using Primer3 (Rozen and Skaletsky 2000). PCR was performed in 96-well PCR plates in a 5- $\mu 1$ solution comprising $2.5 \mu \mathrm{l}(50 \mathrm{ng})$ of template DNA, $2.5 \mu \mathrm{l}$ of KASP $2 \times$ master mix (LGC, Hoddesdon, U.K.), and $0.07 \mu \mathrm{l}$ of primer mix (12 $\mu \mathrm{l}$ of each allele-specific forward primer $[100 \mu \mathrm{M}], 30 \mu \mathrm{l}$ of reverse primer $[100 \mu \mathrm{M}$ ], and $46 \mu \mathrm{l}$ of TRIS [10 mM, pH 8.3]; LGC, Hoddesdon, U.K.). Amplification was performed in a water bathbased thermal cycler instrument (Hydrocycler; LGC, Middlesex, UK) programmed at $94^{\circ} \mathrm{C}$ for $15 \mathrm{~min}, 10$ touchdown cycles of $94^{\circ} \mathrm{C}$ for $20 \mathrm{~s}$ and 61 to $55^{\circ} \mathrm{C}$ for $60 \mathrm{~s}$ (dropping $0.6^{\circ} \mathrm{C}$ per cycle), and 26 cycles of $94^{\circ} \mathrm{C}$ for $20 \mathrm{~s}$ and $55^{\circ} \mathrm{C}$ for $60 \mathrm{~s}$. Genotyping data obtained based on the florescence detected from the KASP assay were viewed and analyzed through KlusterCaller software (LGC Genomics, Beverly, MA, U.S.A.). Complete details on the principles and procedures of the KASP assays are available at https:// biosearch-cdn.azureedge.net/assetsv6/KASP-genotyping-chemistryUser-guide.pdf.

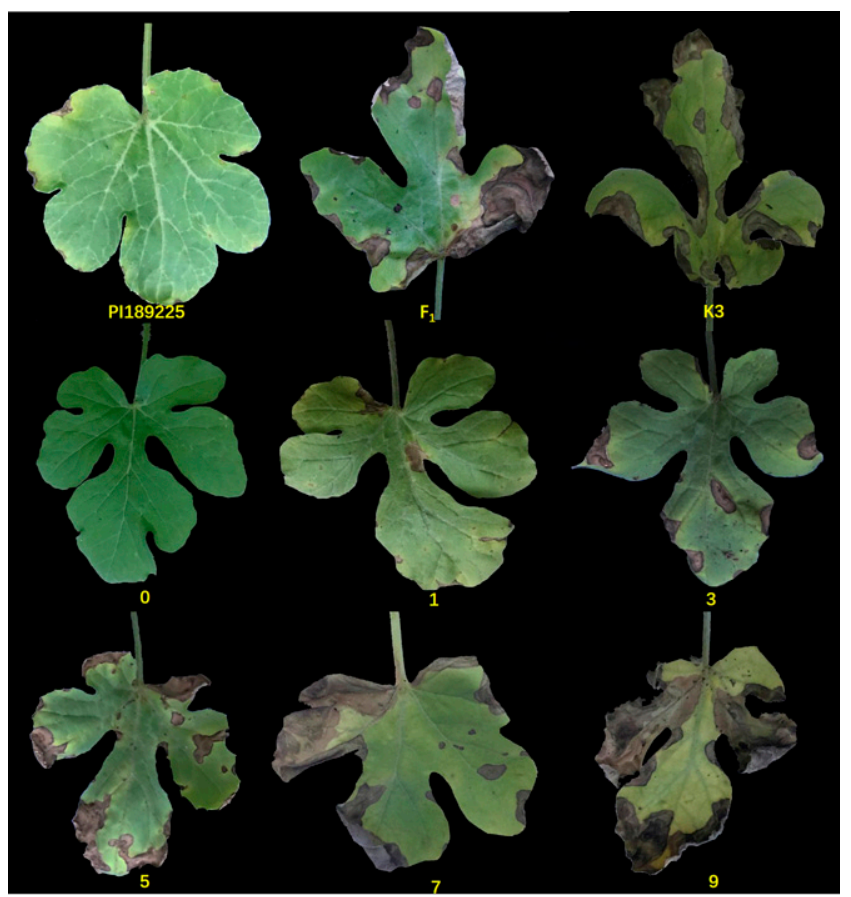

Fig. 1. Gummy stem blight (GSB) reactions on the leaves of resistant parent $\mathrm{Pl} 189225, \mathrm{~F}_{1}$ and susceptible parent $\mathrm{K} 3$, and representative disease rating scales corresponding to $0=$ absence of gummy stem blight (GSB) spots, $1=\leq 5 \%$ GSB spots, $3=>5 \%$ but $\leq 25 \%$ GSB spots, $5=>25 \%$ but $\leq 50$ GSB spots, $7=>50 \%$ but $\leq 75 \%$ GSB spots, and $9=>75 \%$ GSB spots.

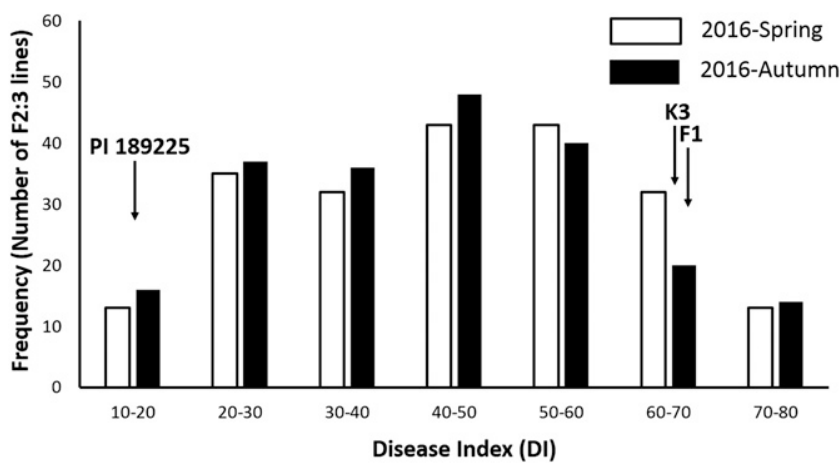

Fig. 2. Frequency distribution of disease index among the $F_{2: 3}$ families derived from the cross $\mathrm{K} 3 \times \mathrm{PI} 189225$ in response to gummy stem blight inoculation in controlled greenhouse conditions in the 2016 spring and autumn seasons.
Linkage map construction and QTL analysis. Linkage map construction and QTL analysis were performed using QTL IciMapping V3.2 (Wang 2009) (http://www.isbreeding.net/default.aspx? aspxerrorpath=/download_software_ICIM.aspx). The linkage map was obtained using the MAP function in software QTL IciMapping 3.2 with a minimum logarithm of odds (LOD) value of 3.0. Recombination values used to map distances in centimorgans were calculated based on the Kosambi mapping function (Kosambi 1943).

The mean DI of GSB of each $\mathrm{F}_{2: 3}$ family calculated from 24 plants per family was used as the phenotypic data for the QTL mapping analysis. QTL analysis was conducted using the BIP functionality (QTL mapping in biparental populations) in QTL IciMapping. The inclusive composite interval mapping of additive (ICIM-ADD) QTL method with mapping parameters of a walking step of 1.0 centimorgan $(\mathrm{cM})$, and a probability of the stepwise regression of 0.001 was used for significance of QTL identification. Significant LOD threshold value was calculated using 1,000 permutations, with a type I error of 0.05 . The confidence interval of the QTL was determined by 1-LOD intervals surrounding the QTL peak. Missing phenotypes were deleted using the 'Deletion' command. The additive effect and phenotypic variance explained of the QTL were also estimated using QTL IciMapping V3.2.

Identification of potential candidate genes. The physical location of the region between the SNP marker KASP_JS9383 and the SNP marker KASP_JS9168 was identified in the watermelon genome sequences and, according to syntenic chromosome relationships among melon, cucumber, and bottle gourd, sequences of the region between the two markers were further used to search the corresponding chromosomes in the reference genome sequence of melon, cucumber, and bottle gourd at the Cucurbit Genomics Database (http://cucurbitgenomics.org/).

RNA isolation and reverse-transcription quantitative PCR analysis. Total RNA was extracted from the leaf tissues of the two parents following the protocol of Tiangen RNAprep Pure FFPE kit (Tiangen Biotech Co., Ltd., Beijing, China) and then converted to cDNA using the PrimeScript RT reagent kit (both from Tiangen Biotech Co., Ltd.). The quantity of the RNA was assessed spectroscopically and the quality was assessed by agarose gel electrophoresis. The qPCR reactions were performed using SYBR Premix ExTaq kit (TaKaRa, Biotechnology Co., Ltd., Dalian, China) in a total volume of $20 \mu l$ containing $10.0 \mu \mathrm{l} 2 \mathrm{X}$ SYBR Premix Ex Taq II (TaKaRa, Biotechnology Co., Ltd.), $2 \mu \mathrm{l}$ cDNA, $1 \mu$ l each primer $(10 \mu \mathrm{M})$ and $6.0 \mu \mathrm{LddH_{2 }} \mathrm{O}$. The PCR was performed using a LightCycler 480 II (Roche Diagnostics, Rotkreuz, Switzerland) and the thermocycling conditions were as follows: denaturation at $95^{\circ} \mathrm{C}$ for $30 \mathrm{~s}$ followed by 40 cycles of $95^{\circ} \mathrm{C}$ for $10 \mathrm{~s}$ and $60^{\circ} \mathrm{C}$ for $30 \mathrm{~s}$, and one cycle of $95^{\circ} \mathrm{C}$ for $15 \mathrm{~s}, 60^{\circ} \mathrm{C}$ for $60 \mathrm{~s}$ and $95^{\circ} \mathrm{C}$ for $15 \mathrm{~s}$ for dissociation. Gene-specific primers were designed using NCBI primer BLAST (https://www.ncbi.nlm.nih.gov/tools/primer-blast/) and the primers were synthesized by TSINGKE Biological Technology Co., Ltd. (Nanjing, China). The primer sequences of the genes are listed in Supplementary Table S1. Three biological replications were used for each parent and each biological replication with three technical replicates. Relative expression levels were calculated using the $2^{-\Delta \Delta \mathrm{Ct}}$ method (Livak and Schmittgen 2001).

\section{Results}

Genetic analysis of GSB resistance in PI 189225. In the greenhouse test under controlled conditions, the PI 189225 seedlings were resistant and exhibited brown necrotic lesions at the sites of infection throughout the leaf at 5 days after inoculation. As the disease developed, the necrotic lesions became darker and were limited to the sites of infection, indicating a resistant response, and the plants were scored with DI. In contrast, the susceptible reaction of the susceptible parent K3 involved the development of large areas of necrosis or extensive chlorosis that became larger and coalesced as the disease progressed, and such plants were scored with DI ranging from 7 to 9 . All of the $\mathrm{F}_{1}$ plants displayed the susceptible reaction, which was similar to that of $\mathrm{K} 3$ (Fig. 1). In the $\mathrm{F}_{2: 3}$ population, the DI data showed a largely normal distribution and continuous variation, with one peak (Fig. 2). ANOVA revealed differences $(P<0.01)$ among the $F_{2: 3}$ 
families for the DI obtained in both the 2016 spring season and 2016 autumn season, which ranged from 13.5 to 77.1 and 14.3 to 76.2 , respectively (Table 1). The correlation analysis showed that the mean DI of GSB from the two seasons were significantly correlated $(r=$ $0.92, P<0.01)$, suggesting the stability of the two measurements of GSB resistance.

Resequencing data analysis and identification of candidate intervals. In total, $63.39 \mathrm{~Gb}$ of clean data of high quality $(\mathrm{Q} 30 \geq$ $95.86 \%$ ) were obtained by filtering and trimming the raw data generated through parental genome resequencing and BSA. The GC content ranged from 35.07 to $36.68 \%$ (Table 2). The clean data from the four samples were aligned to the watermelon reference genome sequence, and the average sequence depths were 51.47 -fold in

Table 1. Means, ranges, least significant differences (LSD), and $P$ values of disease index of the parents and $\mathrm{F}_{2: 3}$ population in the spring and autumn seasons of 2016

\begin{tabular}{lcccccccc}
\hline & \multicolumn{2}{c}{ Parents and $\mathbf{F}_{\mathbf{1}}$} & & \multicolumn{4}{c}{$\mathbf{F}_{2: 3}$ population } \\
\cline { 2 - 3 } Environment & $\mathbf{1 8 9 2 2 5}$ & $\mathbf{K 3}$ & $\mathbf{F}_{\mathbf{1}}$ & & Mean & Range & value & LSD \\
\hline Spring & 14.5 & 67.4 & 66.1 & & $44.5 \pm 16.3$ & $13.5-77.1$ & $<0.01$ & 6.46 \\
Autumn & 15.8 & 63.7 & 62.2 & & $43.2 \pm 16.2$ & $14.3-76.1$ & $<0.01$ & 7.32 \\
\hline
\end{tabular}

susceptible parent (SP), 35.49-fold in resistant parent (RP), 30.25fold in susceptible bulk (SB), and 48.58-fold in resistance bulk (RB) (Table 2). The number of mapped reads was $136,043,523$ $(99.4 \%)$ in SP; 89,955,069 (98.9\%) in RP; 78,109,328 (98.77\%) in $\mathrm{SB}$; and $128,471,984(98.58 \%)$ in RB (Table 2), with an average of $432,579,904$ (98.94\%), indicating a high level of mapping to the reference genome.

In total, 3,500,079, 3,526,565, 199,641, and 3,562,294 SNPs were obtained for RP, RB, SP, and SB, respectively (Table 2). With the criteria for selecting the SNPs that are homozygous for each parent and show polymorphism between the parents, in total, 195,939 high-quality SNPs that are polymorphic between the resistant pool and the susceptible pool were used for subsequent SNP-index and $\Delta$ (SNP-index) calculation. The identification of resistance-related candidate regions was accomplished by screening genotypic frequency differences between the resistant pool and the susceptible pool. One region spanning $5.7 \mathrm{Mb}(10,358,659$ to $16,101,517)$ on chromosome 8 with average $\Delta(\mathrm{SNP}-$ index $)$ values above the confidence value (99\% [red line]) (Fig. 3) were defined as primary regions associated with GSB resistance.

Selection and validation of a SNP subset in a KASP genotyping assay. To further narrow the associated regions, in total, 52 KASP markers were designed from the corresponding sequence of the region harboring SNPs surrounding the resistance loci and

Table 2. Summary of sequencing data and the data aligned to the watermelon reference genome for the parental lines and the resistant and susceptible pools

\begin{tabular}{lcccccrrr}
\hline Samples $^{\mathbf{a}}$ & Clean reads $^{\mathbf{b}}$ & Clean data $^{\mathbf{c}}$ & GC content $(\%)^{\text {Q30 }(\%)}$ & Avg depth $^{\mathbf{d}}$ & \multicolumn{1}{c}{ Reads $^{\mathbf{e}}$} & Mapped reads $(\%)^{\mathbf{f}}$ & SNPs $^{\mathbf{g}}$ \\
\hline RP & $43,505,510$ & $13,051,653,000$ & 36.68 & 97.49 & 35.49 & $90,953,525$ & 98.90 \\
RB & $63,114,485$ & $18,934,345,500$ & 35.49 & 95.86 & 48.58 & $130,321,985$ & $3,500,079$ \\
SP & $66,326,158$ & $11,503,943,100$ & 35.07 & 96.04 & 51.47 & $136,871,441$ & 98.58 \\
SB & $38,346,477$ & $11,503,943,100$ & 35.07 & 90.49 & 30.25 & $79,082,342$ & 99.40 & 98.77 \\
\hline
\end{tabular}

${ }^{\text {a }} \mathrm{SP}=$ susceptible parent, $\mathrm{RP}=$ resistant parent, $\mathrm{SB}=$ susceptible bulk, and $\mathrm{RB}=$ resistance bulk.

$\mathrm{b}$ Total number of pair-end reads in the clean data.

c Total number of bases in the clean data.

d Average read depth of each sample.

e Number of reads aligned to the watermelon reference genome. Both ends are counted separately.

${ }^{f}$ Percentage of reads aligned to the watermelon reference genome.

g Single-nucleotide polymorphisms.

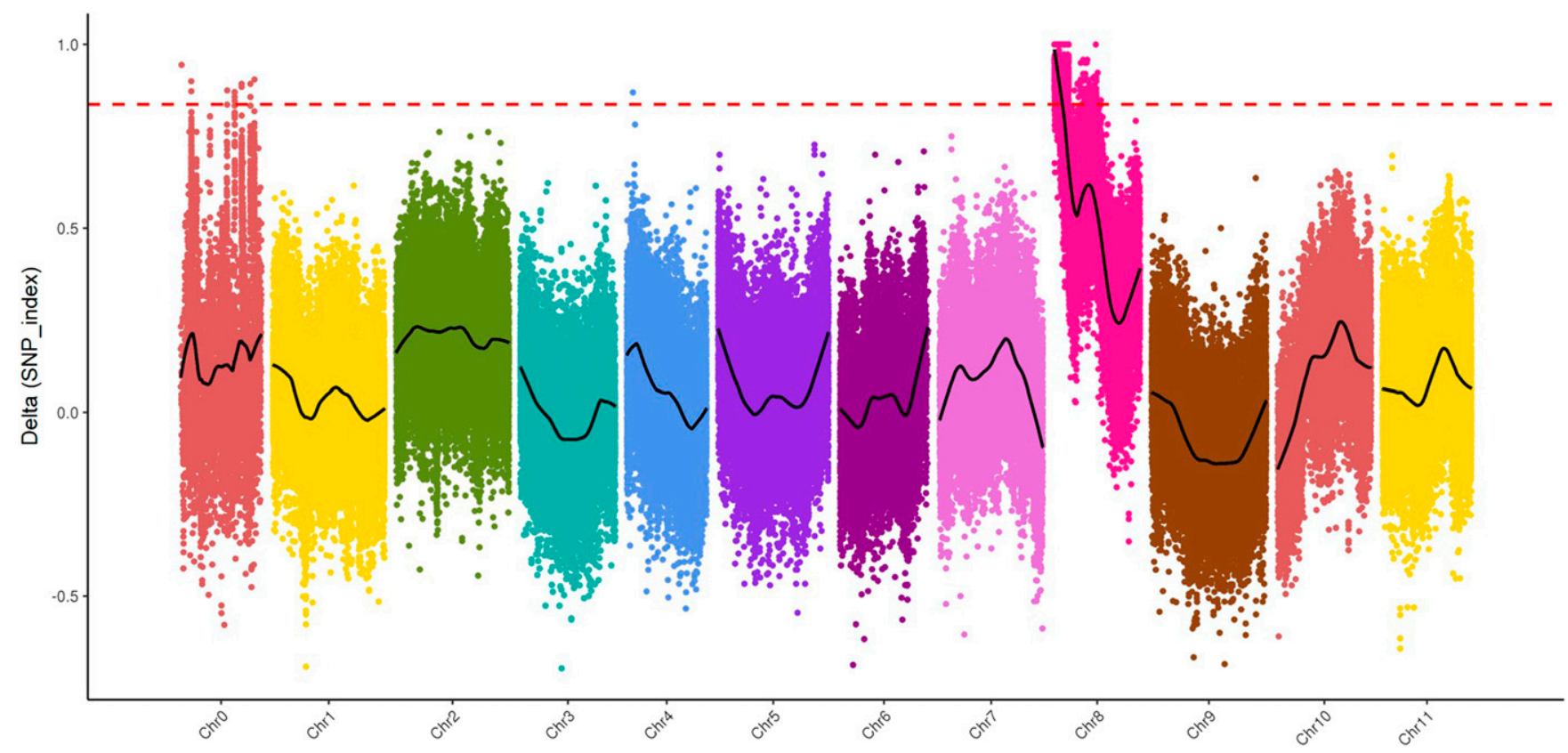

Fig. 3. Graph of $\Delta$ (single-nucleotide polymorphism [SNP]-index) from the analysis of bulked segregant analysis in combination with next-generation sequencing marker-trait association to identify regions of the watermelon genome associated with resistance to gummy stem blight. The $x$-axis represents chromosomal position and the $y$-axis represents $\Delta$ (SNP-index) values. Black lines are average $\Delta$ (SNP-index) values determined by sliding window analysis. The dashed line indicates the association threshold value (0.84) at the significance level of $P<0.01$, which was calculated by Loess regression. 
tested for polymorphisms with the two parental lines and part of the population. Using KASP assays, genotyping results were obtained with 12 SNPs (Table 3), revealing the biallelic codominant polymorphism expected between the resistant and susceptible parents and in the $\mathrm{F}_{2}$ population. The remaining $40 \mathrm{SNPs}$ failed due to nonreadable signals or failed probe design. The QTL analysis showed that one major QTL, designated as Qgsb8.1, was detected in both seasons with LOD peak values of 13.6 and 16.4 in the 2016 spring and autumn seasons, respectively, and a 1-LOD support interval ranging from 10.3 to $12.2 \mathrm{cM}$ on chromosome 8 . It explained $32.42 \%$ (2016 spring season) and $31.54 \%$ (2016 autumn season) of the phenotypic variance with additive effects of -10.7 (2016 spring season) and -11.6 (2016 autumn season), respectively. The negative value of additive effects also confirmed the donor of PI 189225 for the GSB resistance allele. The QTL was located between SNP marker KASP_ JS9383 and SNP marker KASP_JS9168, spanning an interval of approximately $1.9 \mathrm{cM}$, and the region was estimated to be of $571.27 \mathrm{~kb}$ $(11,424,655$ to $11,995,922 \mathrm{bp})$ on chromosome 8 of $C$. lanatus (Fig. 4).

Annotation and orthologous analysis. According to the watermelon gene annotation database (http://cucurbitgenomics.org/organism/ 1 ), the region contains approximately 19 annotated genes, and out of the 19 genes, two showed disease resistance gene analogs, Cla001017 (coiled-coil nucleotide-binding site leucine-rich repeat
[CC-NBS-LRR] resistance protein) and Cla001019 (pathogenesisrelated) (Table 4). The functionality of the other genes in the region includes 1 encoding a RING finger protein, 1 encoding a receptor protein kinase-like protein, 1 encoding a pentatricopeptide repeat protein, 1 encoding Ras small GTPase proteins, 2 encoding a DNA mismatch repair protein, and 11 encoding proteins of unknown function (Table 4). The orthologous genes were also searched in melon, cucumber, and bottle gourd. The 19 annotated genes are orthologous to 8 annotated melon genes, 6 annotated cucumber genes, and 10 annotated bottle gourd genes (Table 2). The two disease-related genes Cla001017 and Cla001019 are orthologous to LsiO8G002220 and Lsi08G002200, respectively, in bottle gourd.

Expression profiles of the candidate genes. We further conducted a reverse-transcription quantitative PCR (RT-qPCR) assay to determine the expression patters of the two candidate genes in the susceptible parent K3 and resistant parent PI 189225 after inoculation with S. cucurbitacearum. The RT-qPCR results demonstrated that the expression of Cla001017 in the K3 was higher than in the PI 189225 before inoculation, and the gene was highly upregulated following inoculation in the K3 (Fig. 5). In contrast, the expression of Cla001017 in PI189225 was first highly induced at $6 \mathrm{~h}$ postinoculation (hpi) and then decreased at 12 and 24 hpi. The relative expression of Cla001019 in the resistant parent PI 189225 was higher than that in the susceptible parent K3 and we found that, after inoculation, Cla001019 showed
B

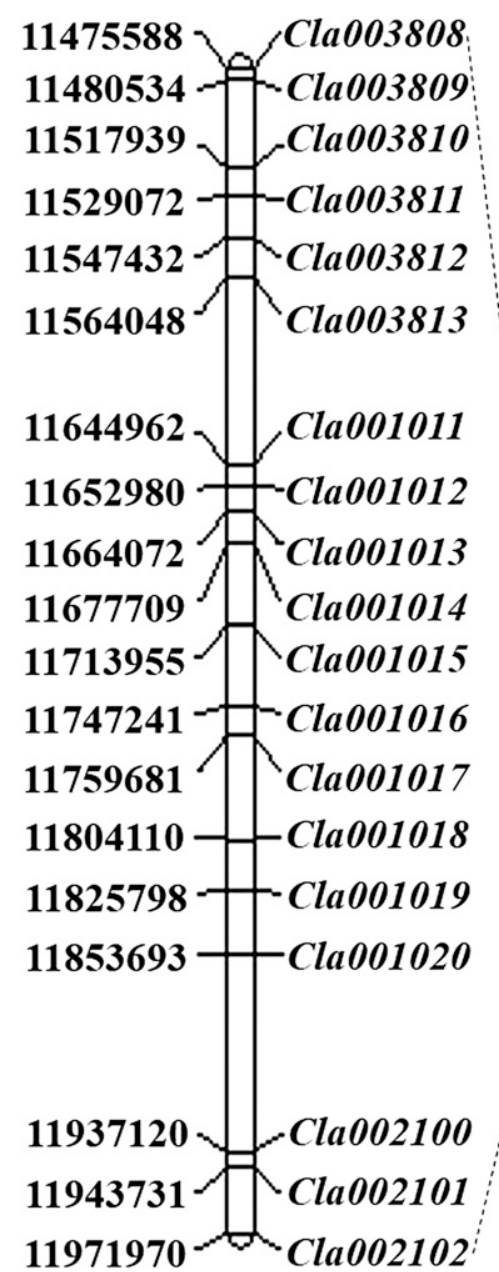

A

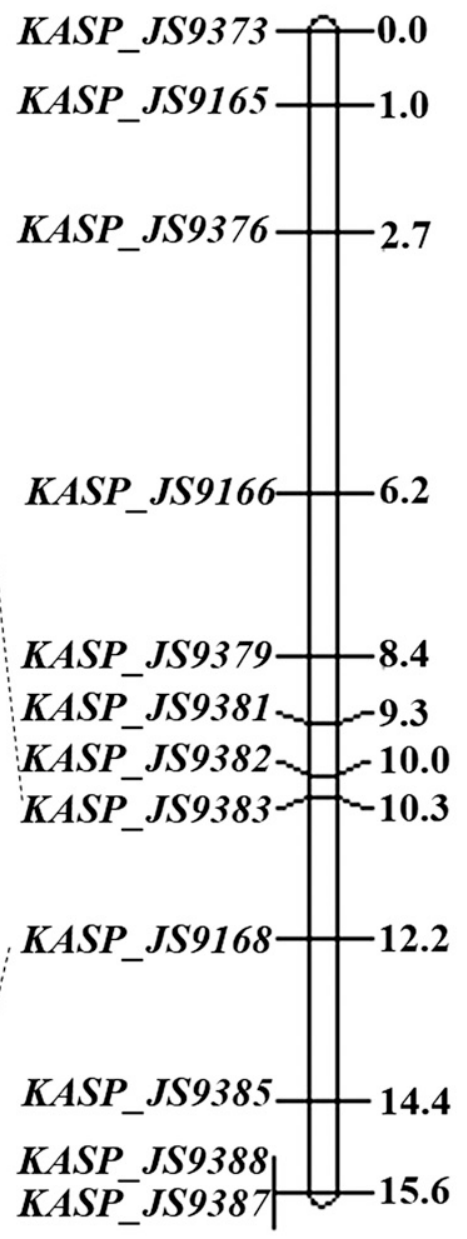

Disease Index

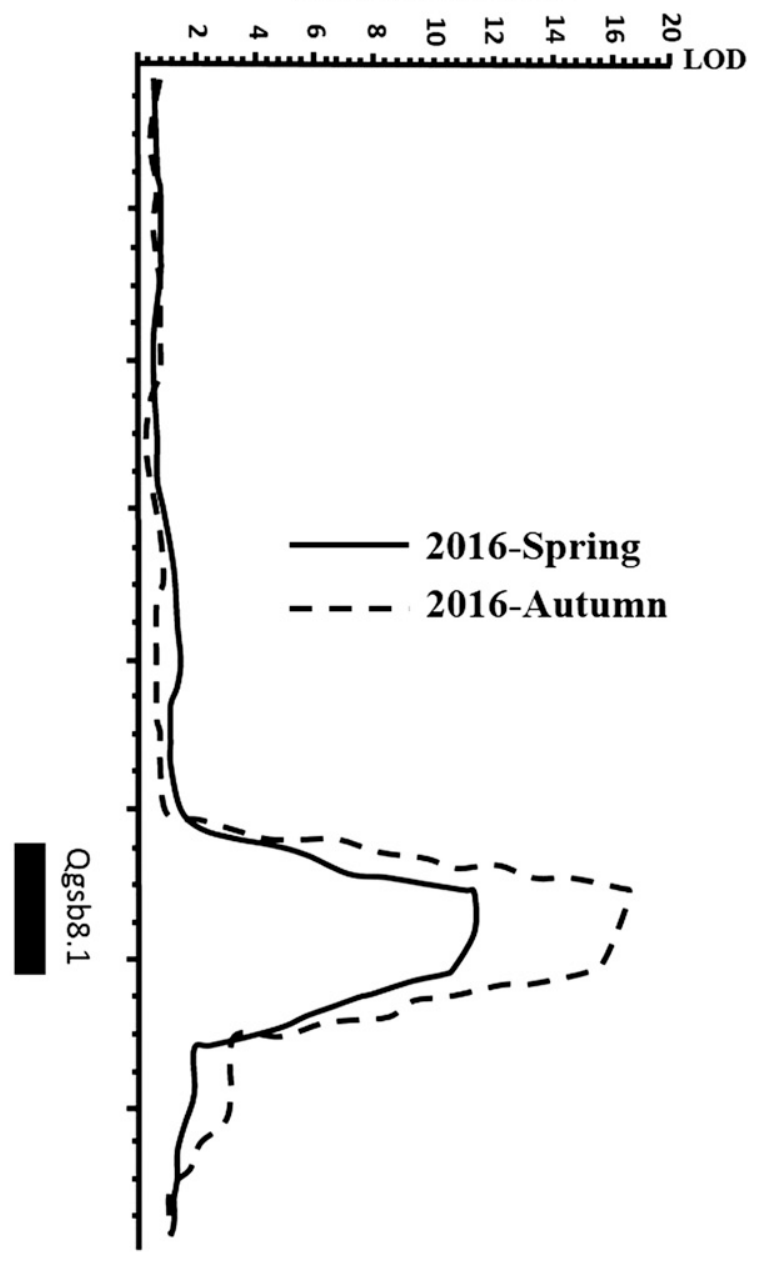

Fig. 4. Genetic map and physical map showing the location of the Qgsb8.1 locus on watermelon chromosome 8 and the candidate genes located in a $571.27-\mathrm{kb}$ region flanked by two closely linked markers. A, Genetic map of watermelon chromosome 8; marker names are indicated on the left side of the map. Map distances (in centimorgans) are shown on the right side. Map position likelihood confidence intervals are shown as a black box with 1-LOD confidence intervals. B, Physical map of candidate genes in the region flanked by the two linked markers; the names of the candidate genes are indicated to the right of watermelon chromosome 8 , and the physical locations are shown on the left side of chromosome 8. KASP = Kompetitive allele-specific PCR. 
much higher relative expression levels at $6 \mathrm{hpi}$ in the resistant parent PI 189225 than in the susceptible parent K3, and that the change trends in relative expression levels were similar to the gene Cla001017 from 6 to 24 hpi in both of the parents (Fig. 5). The above results indicated that the two candidate genes should play important roles in GSB resistance in watermelon.

\section{Discussion}

GSB is one of the most serious foliar diseases of watermelon and can significantly affect yield and fruit quality (Crinò et al. 2007; Keinath 2000; Keinath et al. 2003; Vawdrey 1994). To date, relatively few studies have been performed on the genetics of GSB resistance in watermelon. Among these few studies related to the inheritance of resistance to GSB, watermelon-related studies were first carried out by Norton (1979), who reported that resistance to GSB in watermelon was controlled by one recessive gene $(d b / d b)$. St. Amand and Wehner (2001) reported that the major effect conferred by $d b / d b$ is complemented by the expression of modifier genes, and these genetic factors are weaker than environmental factors. The most recent studies of the genetics of GSB resistance in watermelon were described by Gusmini et al. (2017), who studied the inheritance of resistance to GSB using three PI accessions of watermelon; they reported that the genetic basis of resistance in PI 189225 previously reported by Norton (1979) was more complex than a single recessive gene. They also suggested that the GSB resistance in PI 482283 and PI 526233 may be under the control of a more complex genetic system.

In our previous study, we applied multiple inoculation strategies for GSB resistance on stems and leaves with five different isolates of $S$. cucurbitacearum collected from different places in east China (Li et al. 2015). Different reactions in the stem and leaves of PI 189225 suggest that different genetic factors may influence the host's response to GSB infections in the leaves and stems (data not shown); this possibility was also raised in the studies conducted by Zhang et al. (2017) and Liu et al. (2017), who found that the GSB resistance in the stem and seedlings of cucumber accession PI 183967 was controlled by different QTL on different chromosomes. Although the parental lines employed in our study differed in their resistance to GSB and wide segregation was observed among the $\mathrm{F}_{2: 3}$ families, the corresponding $\mathrm{F}_{2}$ families did not strictly fit the ratio expected under the hypothesis of a single recessive resistance gene.

Another possible reason for the inconsistency with a single resistance gene is that the population in the present study was derived from an interspecific cross, which can result in segregation distortion in some specific regions associated with gamete selection. Segregation distortion is a common phenomenon that can be influenced by factors affecting gametophyte selection (Lyttle 1991; Xu et al. 1997). In the present study, compared with other factors such as marker types, environmental effects, and genetic population types, the interspecific cross was the most likely reason and, in our previous study, a segregation distortion region (SDR) was found on the short arm of chromosome 8 with another $\mathrm{F}_{2}$ population derived from the same parents (Ren et al. 2015). However, whether this deviation from the expected ratio for a single recessive gene is due to segregation distortion or incomplete resistance remains to be examined.

S. cucurbitacearum can infect plants at any stage of development and affects all parts of the host, including the leaves, stems, and fruit.

Table 3. List of Kompetitive allele-specific PCR (KASP) markers used in this study

\begin{tabular}{|c|c|c|c|c|c|}
\hline Marker name & Fluorescent primer & Sequence $\left(5^{\prime}-3^{\prime}\right)$ & Location $^{\mathbf{a}}$ & Allele & $\mathbf{L O D}^{\mathbf{b}}$ \\
\hline \multirow[t]{3}{*}{ KASP_JS9388 } & Allele-specific 1 (FAM) & GCAGTGCCACACAGAAATTGATTG & $13,959,138$ & $\mathrm{C}$ & 1.40 \\
\hline & Allele-specific 2 (HEX) & TTGGCAGTGCCACACAGAAATTGATTA & $\ldots$ & $\mathrm{T}$ & $\ldots$ \\
\hline & Common & GGTTCTGATGCATGTTTGCCACCAT & $\ldots$ & $\ldots$ & $\ldots$ \\
\hline \multirow[t]{3}{*}{ KASP_JS9387 } & Allele-specific 1 (FAM) & AAGAAAAGTTTGTTAAGTTCTTGAGACGA & $13,604,914$ & A & 1.40 \\
\hline & Allele-specific 2 (HEX) & AAGAAAAGTTTGTTAAGTTCTTGAGACGT & $\ldots$ & $\mathrm{T}$ & $\ldots$ \\
\hline & Common & CTCTCAAACAAAAACCCACGAACAATCAA & $\ldots$ & $\ldots$ & $\ldots$ \\
\hline \multirow[t]{3}{*}{ KASP_JS9385 } & Allele-specific 1 (FAM) & TCAGTAGGTAGATTCTCATCAATTAGG & $12,684,112$ & $\mathrm{G}$ & 1.40 \\
\hline & Allele-specific 2 (HEX) & CTCAGTAGGTAGATTCTCATCAATTAGA & $\ldots$ & A & $\ldots$ \\
\hline & Common & CTGCTGATTCTATTCTTGTCTCTATGTCTA & $\ldots$ & $\ldots$ & $\ldots$ \\
\hline \multirow[t]{3}{*}{ KASP_JS9383 } & Allele-specific 1 (FAM) & TCTGCTCTACCATAATGTAAGCCC & $11,424,655$ & $\mathrm{C}$ & 1.19 \\
\hline & Allele-specific 2 (HEX) & TATCTGCTCTACCATAATGTAAGCCT & $\ldots$ & $\mathrm{T}$ & $\ldots$ \\
\hline & Common & TCTCTTCTTAACTTGCCATCTCCCA & $\ldots$ & $\ldots$ & $\ldots$ \\
\hline \multirow[t]{3}{*}{ KASP_JS9382 } & Allele-specific 1 (FAM) & CTTTAAAAAGTTGTAGCATGAGTCATTCA & $11,344,469$ & $\mathrm{~A}$ & 1.10 \\
\hline & Allele-specific 2 (HEX) & TTTAAAAAGTTGTAGCATGAGTCATTCG & $\ldots$ & G & $\ldots$ \\
\hline & Common & GATTTGTGTATGGATTTGTGCCCTTAAATT & $\ldots$ & $\ldots$ & $\ldots$ \\
\hline \multirow[t]{3}{*}{ KASP_JS9381 } & Allele-specific 1 (FAM) & CTCGCTCTCGCTTCCTTTCCTCA & $11,151,442$ & $\mathrm{~T}$ & 1.22 \\
\hline & Allele-specific 2 (HEX) & TCGCTCTCGCTTCCTTTCCTCG & $\ldots$ & $\mathrm{C}$ & $\ldots$ \\
\hline & Common & GTGAGAGAGAGCGAGAGAGATAGAT & $\ldots$ & $\ldots$ & \\
\hline \multirow[t]{3}{*}{ KASP_JS9379 } & Allele-specific 1 (FAM) & CTCCGACTTCTAGAGAAGAAGG & $10,659,204$ & G & 1.22 \\
\hline & Allele-specific 2 (HEX) & CCTCCGACTTCTAGAGAAGAAGA & $\ldots$ & A & $\ldots$ \\
\hline & Common & GAGAGCCAAAGTGAGCTTAAATCAATGAT & $\ldots$ & $\ldots$ & $\ldots$ \\
\hline \multirow{3}{*}{ KASP_JS9376 } & Allele-specific 1 (FAM) & TGCCCAGAAATTAAGGATGCCTATGA & $9,024,470$ & $\mathrm{~T}$ & 1.65 \\
\hline & Allele-specific 2 (HEX) & CCCAGAAATTAAGGATGCCTATGC & $\ldots$ & G & $\ldots$ \\
\hline & Common & TCTTAGCAATCTTATTCCTATGCTTTTAAT & $\ldots$ & $\ldots$ & $\ldots$ \\
\hline \multirow[t]{3}{*}{ KASP_JS9373 } & Allele-specific 1 (FAM) & GTGACATTAGGAAAAAGTAAATGGAAAAAGA & $7,892,440$ & $\mathrm{~T}$ & 1.05 \\
\hline & Allele-specific 2 (HEX) & TGACATTAGGAAAAAGTAAATGGAAAAAGG & $\ldots$ & $\mathrm{C}$ & $\ldots$ \\
\hline & Common & CGGCGCTACAAATCATATGCAGGTA & $\ldots$ & $\ldots$ & $\ldots$ \\
\hline \multirow[t]{3}{*}{ KASP_JS9168 } & Allele-specific 1 (FAM) & TGAACCAATATTTAGCCTATCAGACC & $11,995,922$ & $\mathrm{C}$ & 1.19 \\
\hline & Allele-specific 2 (HEX) & ATTTGAACCAATATTTAGCCTATCAGACT & $\ldots$ & $\mathrm{T}$ & $\ldots$ \\
\hline & Common & CACAACCATAGGTGGTCTTGGACAT & $\ldots$ & $\ldots$ & \\
\hline \multirow[t]{3}{*}{ KASP_JS9166 } & Allele-specific 1 (FAM) & GTTTGAACGCATGATGGTATTGTATAGT & $9,506,943$ & $\mathrm{~T}$ & 1.57 \\
\hline & Allele-specific 2 (HEX) & TTTGAACGCATGATGGTATTGTATAGC & $\ldots$ & $\mathrm{C}$ & $\ldots$ \\
\hline & Common & GAACATTCTCAAAACCTTATGCTTATCTTT & $\ldots$ & $\ldots$ & $\ldots$ \\
\hline \multirow[t]{3}{*}{ KASP_JS9165 } & Allele-specific 1 (FAM) & AAATGTTATATGTGCCAAAATTGGAGTTC & $8,429,182$ & $\mathrm{C}$ & 1.01 \\
\hline & Allele-specific 2 (HEX) & AAAAAATGTTATATGTGCCAAAATTGGAGTTT & $\ldots$ & $\mathrm{T}$ & $\ldots$ \\
\hline & Common & CAAGTTCTTAGTCAACTTAGTCACATACAA & $\ldots$ & $\ldots$ & $\ldots$ \\
\hline
\end{tabular}

\footnotetext{
${ }^{\text {a }}$ Location on chromosome 8.
}

${ }^{b}$ Logarithm of odds. 
Resistance to GSB disease in cucurbits is typically evaluated using spray inoculation with a conidial suspension at the four- to six-leaf stage of seedlings (Boyhan et al. 1994a; St. Amand and Wehner 1995a,b; Van Der Meer et al. 1978; van Steekelenburg 1981; Wehner and St. Amand 1993; Zhang et al. 1995, 1997). In the host and pathogen system, apart from the resistance in the host, other important factors favorable for GSB infection include temperature, humidity (particularly the presence of discontinuous water droplets on the foliage), and the length of incubation time (Arny and Rowe 1991; St. Amand and Wehner 1995b; Wehner and St. Amand 1993; Zhang et al. 1997). In our preliminary experiment, the resistant parent and the susceptible parent were tested for differences in pathogenicity and aggressiveness in controlled conditions (unpublished data) with six isolates that were selected as the most aggressive based on our previous work (Li et al. 2015), and isolate JS002, which was also able to sporulate abundantly, was chosen for disease phenotyping. To simplify the possible complex disease resistance in PI 189225, we used the optimized inoculation method and only tested the GSB disease on leaves. In the present study, we also applied the foliar-spray inoculation method, and we kept the inoculated seedlings at $100 \%$ $\mathrm{RH}$ for approximately $24 \mathrm{~h}$, which resulted in a significant difference in resistance between the resistant parent PI 189225 and the susceptible parent K3. However, when the inoculated plants were kept for $48 \mathrm{~h}$, both the resistant parent PI 189225 and the susceptible parent K3 were susceptible, with little difference in resistance (unpublished data). For most foliar fungal diseases, the presence of tiny, discontinuous water droplets on the foliage is important in bringing the germinating spores close to the leaf surface for initial infection, and continuous $100 \% \mathrm{RH}$ is required for subsequent lesion expansion (Bushnell 1972). Arny and Rowe (1991) also reported that $1 \mathrm{~h}$ of free water on leaves was sufficient for infection and that lesion expansion required continued leaf wetness in the infection of cucumber by $S$. cucurbitacearum. Thus, the inoculation method used in the present study was proper for phenotyping the responses to GSB disease in the segregating population. The possible disease resistance in stems could also be a valuable aspect of the disease resistance in PI 189225, and identification and molecular mapping of the resistance in stems could be tested later for comparison between these two kinds of resistance in the same accession.

In the present study, we mapped the resistance locus within the interval of $571.27 \mathrm{~kb}$ flanked by the SNP markers KASP_JS9383 and KASP_JS9168 on the short arm of chromosome 8 by using BSA-seq

Table 4. Positions and annotations of candidate genes in the genomic region of gummy stem blight resistance quantitative trait locus $Q g s b 8.1$ and the corresponding orthologous genes in melon, cucumber, and bottle gourd ${ }^{\mathrm{a}}$

\begin{tabular}{|c|c|c|c|c|c|c|}
\hline Gene names & Start position & End position & Annotation & Melon (DHL92) & $\begin{array}{l}\text { Cucumber } \\
\text { (PI 183967) }\end{array}$ & $\begin{array}{c}\text { Bottle gourd } \\
\text { (USVL1VR-Ls) }\end{array}$ \\
\hline Cla003808 & $11,475,588$ & $11,476,601$ & Unknown protein & MELO3C010590 & CSPIO6G02740 & Lsi08G002710 \\
\hline Cla003809 & $11,480,534$ & $11,480,695$ & Unknown protein & - & - & - \\
\hline Cla003810 & $11,517,939$ & $11,518,190$ & Unknown protein & - & - & - \\
\hline Cla003811 & $11,529,072$ & $11,529,810$ & Unknown protein & - & - & - \\
\hline Cla003812 & $11,547,432$ & $11,547,788$ & Unknown protein & - & - & - \\
\hline Cla003813 & $11,564,048$ & $11,564,476$ & Unknown protein & - & - & - \\
\hline Cla001011 & $11,644,962$ & $11,648,496$ & RING finger protein & MELO3C025008 & CSPI06G02530 & Lsi08G002360 \\
\hline Cla001012 & $11,652,980$ & $11,656,861$ & DNA mismatch repair protein & MELO3C025009 & CSPIO6G02520 & Lsi08G002350 \\
\hline Cla001013 & $11,664,076$ & $11,664,884$ & DNA mismatch repair protein & MELO3C025010 & - & - \\
\hline Cla001014 & $11,677,709$ & $11,679,703$ & Receptor protein kinase-like & MELO3C025012 & CSPIO6G02510 & Lsi08G002340 \\
\hline Cla001015 & $11,713,055$ & $11,713,339$ & Unknown protein & - & - & - \\
\hline Cla001016 & $11,747,241$ & $11,749,340$ & Pentatricopeptide repeat protein & - & - & LsiO8G002230 \\
\hline Cla001017 & $11,759,681$ & $11,762,959$ & CC-NBS-LRR resistance protein ${ }^{\mathrm{b}}$ & - & - & Lsi08G002220 \\
\hline Cla001018 & $11,804,110$ & $11,807,365$ & Unknown protein & MELO3C025014 & CSPI06G02500 & Lsi08G002210 \\
\hline Cla001019 & $11,825,798$ & $11,827,654$ & $\begin{array}{l}\text { Thaumatin-like protein and } \\
\text { pathogenesis-related protein }\end{array}$ & - & - & Lsi08G002200 \\
\hline Cla001020 & $11,853,693$ & $11,857,508$ & Ras-related protein & $\begin{array}{l}\text { MELO3C025015 or } \\
\text { MELO3C011704 }\end{array}$ & CSPIO6G02490 & $\begin{array}{l}\text { Lsi08G002190 or } \\
\text { Lsi08G002830 }\end{array}$ \\
\hline Cla002100 & $11,937,120$ & $11,937,422$ & Unknown protein & - & - & - \\
\hline Cla002101 & $11,943,731$ & $11,944,738$ & Unknown protein & - & - & - \\
\hline Cla002102 & $11,971,970$ & $11,972,143$ & Unknown protein & - & - & - \\
\hline
\end{tabular}

a Symbol: - indicates no hit.

b CC-NBS-LRR = coiled-coil nucleotide-binding site leucine-rich repeat.

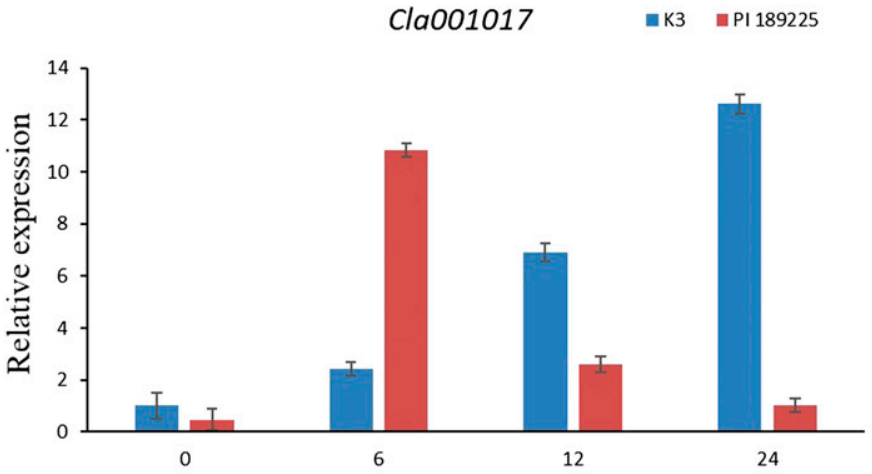

Hours post inoculation (hpi)

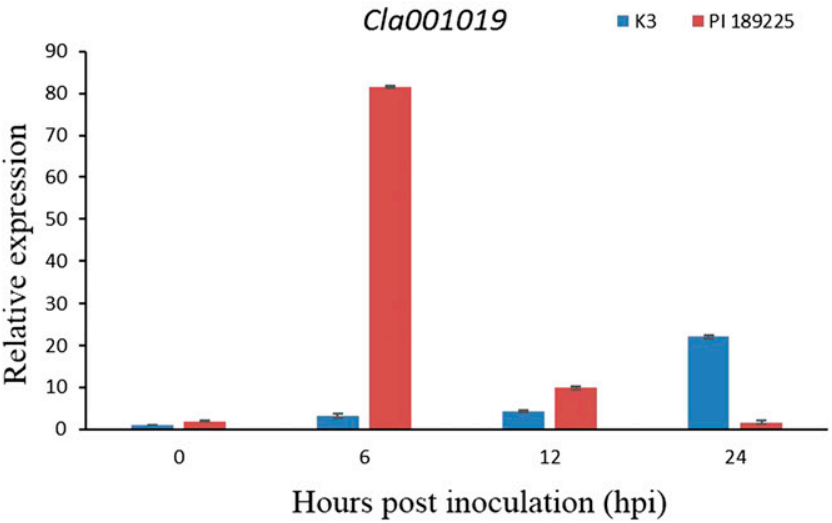

Hours post inoculation (hpi)

Fig. 5. Expression profiles of the two candidate genes (Cla001017 and Cla001019) in susceptible parent K3 and resistant parent PI 189225 after inoculation of Stagonosporopsis cucurbitacearum via reverse-transcription quantitative PCR. 
and KASP marker analysis. The physical location of the region based on the watermelon genome sequence (Guo et al. 2013) indicated that this region contained only one resistance-related gene, Cla001017, annotated as encoding the CC-NBS-LRR resistance protein containing the InterPro domain IPR002182 NB-ARC, suggesting that the resistance locus was close to the Cla001017 locus or that it was the Cla001017 gene. Another possible reason for only one resistancerelated gene in the region is that $C$. lanatus and $C$. amarus are different species and only the $C$. lanatus genome was used for this genetic analysis. The gene conferring GSB resistance may not be listed in the candidate genes because it may not exist in C. lanatus. Moreover, the presence of an SDR also influences the estimation of recombination frequency and, thus, may decrease the accuracy of gene or QTL mapping. An area containing 3 or more skewed markers was defined as an SDR. According to the results of genomic variance analysis of SDRs (Ren et al. 2015), the QTL for GSB resistance identified in the present study were located in the middle of SDR8.1 on chromosome 8. All 45 bin markers in SDR8.1, including the bin marker SNP_ chr08_bin10 between the SNP markers KASP_JS9383 and KASP_ JS9168, were skewed in favor of susceptible parent K3,indicating that this QTL region in SDR8.1 is a hot spot for genetic variation between $C$. lanatus and $C$. amarus. Therefore, care should be taken in identification and mapping of genes or QTL from crosses between feral and cultivated types of crops.

There is collinearity among watermelon chromosome 8 , melon chromosome 3, and cucumber chromosomes 2 and 6 (Huang et al. 2009; Li et al. 2011). Based on the collinearity relationship, one QTL $(g s b-s 2.1)$ on chromosome 2 and 3 QTL $(g s b-s 6.1, g s b$ $s 6.2$, and $g s b$-s6.3) on chromosome 6 for resistance to GSB in cucumber stems have been detected (Zhang et al. 2017), and one QTL ( $g s b 6.1$ ) on chromosome 6 for resistance to GSB in cucumber seedlings has been detected (Liu et al. 2017). Lou et al. (2013) also reported that the one QTL for resistance to GSB in cucumber was identified on chromosome 6 . According to the reference genome sequence 97103, disease-resistance genes are also enriched in the distal part of the short arm of chromosome 8, which is near the interval of the resistance gene; this result suggested that the resistance gene may be associated with the QTL for GSB detected in melon and cucumber or with other resistance gene clusters. However, the actual relationship between these loci requires additional fine mapping.

In summary, this is the first report on the genetics and mapping of resistance to GSB in watermelon, and the resistance gene and linked molecular markers mapped in this study are important for watermelon breeding programs and will contribute to marker-assisted selection procedures in watermelon resistance breeding. Additionally, the markers can be employed in further fine mapping and positional cloning to gain a more complete understanding of resistance to GSB in PI 189225.

\section{Acknowledgments}

We thank Genepioneer Biotechnologies Company for their technical support

\section{Literature Cited}

Abe, A., Kosugi, S., Yoshida, K., Natsume, S., Takagi, H., Kanzaki, H., Matsumura, H., Yoshida, K., Mitsuoka, C., and Tamiru, M. 2012. Genome sequencing reveals agronomically important loci in rice using MutMap. Nat. Biotechnol. 30:174-178.

Arny, C. J., and Rowe, R. C. 1991. Effects of temperature and duration of surface wetness on spore production and infection of cucumbers by Didymella bryoniae. Phytopathology 81:206-209.

Boyhan, G., Norton, J., and Abrahams, B. 1994a. Screening for resistance to anthracnose (race 2), gummy stem blight, and root knot nematode in watermelon germplasm. Cucurbit Genet. Coop. Rep. 17:106-110.

Boyhan, G., Norton, J., Abrahams, B., and Wen, H. 1994b. A new source of resistance to anthracnose (Race 2) in watermelon. HortScience 29:111-112.

Brown, J., Pirrung, M., and McCue, L. A. 2017. FQC Dashboard: Integrates FastQC results into a web-based, interactive, and extensible FASTQ quality control tool. Bioinformatics 33:3137-3139.

Bushnell, W. 1972. Physiology of fungal haustoria. Annu. Rev. Phytopathol. 10: 151-176.

Crinò, P., Bianco, C. L., Rouphael, Y., Colla, G., Saccardo, F., and Paratore, A. 2007. Evaluation of rootstock resistance to fusarium wilt and gummy stem blight and effect on yield and quality of a grafted 'Inodorus' melon. HortScience 42:521-525.
Guo, S., Zhang, J., Sun, H., Salse, J., Lucas, W. J., Zhang, H., Zheng, Y., Mao, L., Ren, Y., and Wang, Z. 2013. The draft genome of watermelon (Citrullus lanatus) and resequencing of 20 diverse accessions. Nat. Genet. 45:51-58.

Gusmini, G., Rivera-Burgos, L. A., and Wehner, T. C. 2017. Inheritance of resistance to gummy stem blight in watermelon. HortScience 52:1477-1482.

Gusmini, G., Song, R., and Wehner, T. C. 2005. New sources of resistance to gummy stem blight in watermelon. Crop Sci. 45:582-588.

Haase, N. J., Beissinger, T., Hirsch, C. N., Vaillancourt, B., Deshpande, S., Barry, K., Buell, C. R., Kaeppler, S. M., and de Leon, N. 2015. Shared genomic regions between derivatives of a large segregating population of maize identified using bulked segregant analysis sequencing and traditional linkage analysis. G3: Genes Genomes Genet. 5:1593-1602.

Huang, S., Li, R., Zhang, Z., Li, L., Gu, X., Fan, W., Lucas, W. J., Wang, X., Xie, B., and $\mathrm{Ni}, \mathrm{P} .2009$. The genome of the cucumber, Cucumis sativus L. Nat. Genet. 41:1275-1281.

Keinath, A. P. 2000. Effect of protectant fungicide application schedules on gummy stem blight epidemics and marketable yield of watermelon. Plant Dis. 84:254-260

Keinath, A. P., Farnham, M. W., and Zitter, T. A. 1995. Morphological, pathological, and genetic differentiation of Didymella bryoniae and Phoma spp. isolated from cucurbits. Phytopathology 85:364-369.

Keinath, A. P., Somai, B. M., and Dean, R. A. 2003. Method of diagnosing gummy stem blight in plants using a polymerase chain reaction assay. United States Patent 6610487. http://www.freepatentsonline.com/6610487.html

Kim, S., Kim, C.-W., Park, M., and Choi, D. 2015. Identification of candidate genes associated with fertility restoration of cytoplasmic male-sterility in onion (Allium cepa L.) using a combination of bulked segregant analysis and RNA-seq. Theor. Appl. Genet. 128:2289-2299.

Kosambi, D. D. 1943. The estimation of map distances from recombination values. Ann. Eugen. 12:172-175.

Levi, A., Thomas, C. E., Keinath, A. P., and Wehner, T. C. 2001a. Genetic diversity among watermelon (Citrullus lanatus and Citrullus colocynthis) accessions. Genet. Resour. Crop Evol. 48:559-566.

Levi, A., Thomas, C. E., Wehner, T. C., and Zhang, X. 2001b. Low genetic diversity indicates the need to broaden the genetic base of cultivated watermelon. HortScience 36:1096-1101.

Li, D., Cuevas, H. E., Yang, L., Li, Y., Garcia-Mas, J., Zalapa, J., Staub, J. E., Luan, F., Reddy, U., and He, X. 2011. Syntenic relationships between cucumber (Cucumis sativus L.) and melon (C. melo L.) chromosomes as revealed by comparative genetic mapping. BMC Genomics 12: Article 396.

Li, H., and Durbin, R. 2009. Fast and accurate short read alignment with BurrowsWheeler transform. Bioinformatics 25:1754-1760.

Li, P. F., Ren, R. S., Yao, X. F., Xu, J. H., Babu, B., Paret, M. L., and Yang, X. P. 2015. Identification and characterization of the causal agent of gummy stem blight from muskmelon and watermelon in East China. J. Phytopathol. 163: 314-319.

Liu, S., Shi, Y., Miao, H., Wang, M., Li, B., Gu, X., and Zhang, S. 2017. Genetic analysis and QTL mapping of resistance to gummy stem blight in Cucumis sativus seedling stage. Plant Dis. 101:1145-1152.

Liu, S., Yeh, C.-T., Tang, H. M., Nettleton, D., and Schnable, P. S. 2012. Gene mapping via bulked segregant RNA-Seq (BSR-Seq). PLoS One 7:e36406.

Livak, K., and Schmittgen, T. 2001. Analysis of relative gene expression data using real-time quantitative PCR and the $2^{-\Delta \Delta C T}$ method. Methods 25: 402-408.

Lou, L., Wang, H., Qian, C., Liu, J., Bai, Y., and Chen, J. 2013. Genetic mapping of gummy stem blight (Didymella bryoniae) resistance genes in Cucumis sativus-hystrix introgression lines. Euphytica 192:359-369.

Lu, H., Lin, T., Klein, J., Wang, S., Qi, J., Zhou, Q., Sun, J., Zhang, Z., Weng, Y., and Huang, S. 2014. QTL-seq identifies an early flowering QTL located near flowering locus T in cucumber. Theor. Appl. Genet. 127:1491-1499.

Lyttle, T. W. 1991. Segregation distorters. Annu. Rev. Genet. 25:511-581.

Mascher, M., Jost, M., Kuon, J.-E., Himmelbach, A., Aßfalg, A., Beier, S., Scholz, U., Graner, A., and Stein, N. 2014. Mapping-by-sequencing accelerates forward genetics in barley. Genome Biol. 15: Article R78.

McKenna, A., Hanna, M., Banks, E., Sivachenko, A., Cibulskis, K., Kernytsky, A. Garimella, K., Altshuler, D., Gabriel, S., and Daly, M. 2010. The Genome Analysis Toolkit: A MapReduce framework for analyzing next-generation DNA sequencing data. Genome Res. 20:1297-1303.

Mokry, M., Nijman, I. J., van Dijken, A., Benjamins, R., Heidstra, R., Scheres, B., and Cuppen, E. 2011. Identification of factors required for meristem function in Arabidopsis using a novel next generation sequencing fast forward genetics approach. BMC Genomics 12: Article 256.

Norton, J. 1979. Inheritance of resistance to gummy stem blight [caused by Didymella bryoniae] in watermelon. HortScience 14:630-632.

Power, H., Pavlasek, S., Ellison, H., Sellers, L., and Peay, J. 1992. South Carolina vegetable statistics: 1991. AE Department of Agricultural Economics and Rural Sociology, South Carolina Agricultural Experiment Station, Clemson University 92:472.

Ren, R., Ray, R., Li, P., Xu, J., Zhang, M., Liu, G., Yao, X., Kilian, A., and Yang, X. 2015. Construction of a high-density DArTseq SNP-based genetic map and identification of genomic regions with segregation distortion in a genetic 
population derived from a cross between feral and cultivated-type watermelon. Mol. Genet. Genomics 290:1457-1470.

Rozen, S., and Skaletsky, H. 2000. Primer3 on the WWW for general users and for biologist programmers. Methods Mol. Biol. 132:365-386.

Silva, J., Scheffler, B., Sanabria, Y., De Guzman, C., Galam, D., Farmer, A., Woodward, J., May, G., and Oard, J. 2012. Identification of candidate genes in rice for resistance to sheath blight disease by whole genome sequencing. Theor. Appl. Genet. 124:63-74.

Sitterly, W., and Keinath, A. 1996. Gummy stem blight. Pages 27-28 in: Compendium of Cucurbit Diseases. T. A. Zitter, D. L. Hopkins, and C. E. Thomas, eds. APS Press, St. Paul, MN

Sowell, G., and Pointer, G. R. 1962. Gummy stem blight resistance of introduced watermelons. Plant Dis. Rep. 46:883-885.

St. Amand, P. C., and Wehner, T. C. 1995a. Greenhouse, detached-leaf, and field testing methods to determine cucumber resistance to gummy stem blight. J. Am. Soc. Hortic. Sci. 120:673-680.

St. Amand, P. C., and Wehner, T. C. 1995b. Eight isolates of Didymella bryoniae from geographically diverse area exhibit variation in virulence but no isolate by cultivar interaction on Cucumis sativus. Plant Dis. 79:1136-1139.

St. Amand, P. C., and Wehner, T. C. 2001. Generation means analysis of leaf and stem resistance to gummy stem blight in cucumber. J. Am. Soc. Hortic. Sci. 126:95-99.

Stewart, J. E., Turner, A. N., and Brewer, M. T. 2015. Evolutionary history and variation in host range of three Stagonosporopsis species causing gummy stem blight of cucurbits. Fungal Biol. 119:370-382.

Takagi, H., Abe, A., Yoshida, K., Kosugi, S., Natsume, S., Mitsuoka, C., Uemura, A., Utsushi, H., Tamiru, M., and Takuno, S. 2013. QTL-seq: Rapid mapping of quantitative trait loci in rice by whole genome resequencing of DNA from two bulked populations. Plant J. 74:174-183.

Tetteh, A. Y., Wehner, T. C., and Davis, A. R. 2010. Identifying resistance to powdery mildew race $2 \mathrm{~W}$ in the USDA-ARS watermelon germplasm collection. Crop Sci. 50:933-939.

Tetteh, A. Y., Wehner, T. C., and Davis, A. R. 2013. Inheritance of resistance to powdery mildew race 2 in Citrullus lanatus var. lanatus. HortScience 48:1227-1230.

Van Der Meer, Q., Van Bennekom, J., and Van Der Giessen, A. 1978. Gummy stem blight resistance of cucumbers (Cucumis sativus L.). Euphytica 27: 861-864.

van Steekelenburg, N. A. M. 1981. Comparison of inoculation methods with Didymella bryoniae on Cucumis sativus. Euphytica 30:515-520.

van Steekelenburg, N. A. M. 1983. Epidemiological aspects of Didymella bryoniae, the cause of stem and fruit rot of cucumber. Neth. J. Plant Pathol. 89:75-86.

van Steekelenburg, N. A. M. 1984. Influence of ventilation temperature and low ventilation rates on incidence of Didymella bryoniae in glasshouse cucumbers. Acta Hortic. 156:189-198. doi:

van Steekelenburg, N. A. M. 1985a. Influence of time of transition from night to day temperature regimes on incidence of Didymella bryoniae and influence of the disease on growth and yield of glasshouse cucumbers. Neth. J. Plant Pathol. 91:225-233.

van Steekelenburg, N. A. M. 1985b. Influence of humidity on incidence of Didymella bryoniae on cucumber leaves and growing tips under controlled environmental conditions. Neth. J. Plant Pathol. 91:277-283.

Vawdrey, L. 1994. Evaluation of fungicides and cultivars for control of gummy stem blight of rockmelon caused by Didymella bryoniae. Aust. J. Exp. Agric. 34:1191-1195.

Wang, J. 2009. Inclusive composite interval mapping of quantitative trait genes. Acta Agron. Sin. 35:239-245.

Wang, Y., Xiao, L., Guo, S., An, F., and Du, D. 2016. Fine mapping and wholegenome resequencing identify the seed coat color gene in Brassica rapa. PLoS One 11:e0166464.

Wehner, T. C., and St. Amand, P. C. 1993. Field tests for cucumber resistance to gummy stem blight in North Carolina. HortScience 28:327-329.

Xu, J., Yuan, Y., Xu, Y., Zhang, G., Guo, X., Wu, F., Wang, Q., Rong, T., Pan, G., and Cao, M. 2014. Identification of candidate genes for drought tolerance by whole-genome resequencing in maize. BMC Plant Biol. 14:83.

Xu, Y., Zhu, L., Xiao, J., Huang, N., and McCouch, S. 1997. Chromosomal regions associated with segregation distortion of molecular markers in $\mathrm{F} 2$, backcross, doubled haploid, and recombinant inbred populations in rice (Oryza sativa L.). Mol. Gen. Genet. 253:535-545.

Yang, X., Ren, R., Ray, R., Xu, J., Li, P., Zhang, M., Liu, G., Yao, X., and Kilian, A. 2016. Genetic diversity and population structure of core watermelon (Citrullus lanatus) genotypes using DArTseq-based SNPs. Plant Genet. Resour. 14:226-233.

Yao, Y., Li, K., Liu, H., Duncan, R. W., Guo, S., Xiao, L., and Du, D. 2017. Whole-genome re-sequencing and fine mapping of an orange petal color gene (Bnpc1) in spring Brassica napus L. to a 151-kb region. Euphytica 213 165

Zhang, H., Yi, H., Wu, M., Zhang, Y., Zhang, X., Li, M., and Wang, G. 2016. Mapping the flavor contributing traits on "Fengwei Melon" (Cucumis melo L.) chromosomes using parent resequencing and super bulked-segregant analysis. PLoS One 11:e0148150.

Zhang, S., Liu, S., Miao, H., Shi, Y., Wang, M., Wang, Y., Li, B., and Gu, X. 2017. Inheritance and QTL mapping of resistance to gummy stem blight in cucumber stem. Mol. Breed. 37:49.

Zhang, Y., Anagnostou, K., Kyle, M., and Zitter, T. A. 1995. Seedling screens for resistance to gummy stem blight in squash. Cucurbit Genet. Coop. Rep. 18: 59-61.

Zhang, Y., Kyle, M., Anagnostou, K., and Zitter, T. A. 1997. Screening melon (Cucumis melo) for resistance to gummy stem blight in the greenhouse and field. HortScience 32:117-121.

Zhao, Z., Xiao, L., Xu, L., Xing, X., Tang, G., and Du, D. 2017. Fine mapping the BjPl1 gene for purple leaf color in B2 of Brassica juncea L. through comparative mapping and whole-genome re-sequencing. Euphytica 213:80. 